\title{
Médiévales
}

Langues, Textes, Histoire

67 | automne 2014

Histoires de Bohême

\section{«Oyez, fidèles, la ruse diabolique ! » La ruse et la trahison dans la chanson polémique de l'époque hussite}

"Listen, you faithful, the evil ploy!" Ploy and Betrayal in Polemic Songs of the Hussite period

\section{Sára Vybíralová}

\section{OpenEdition \\ Journals}

Édition électronique

URL : https://journals.openedition.org/medievales/7397

DOI : 10.4000/medievales.7397

ISSN : $1777-5892$

\section{Éditeur}

Presses universitaires de Vincennes

\section{Édition imprimée}

Date de publication : 31 décembre 2014

Pagination : 67-84

ISBN : 978-2-84292-422-5

ISSN : 0751-2708

\section{Référence électronique}

Sára Vybíralová, « « Oyez, fidèles, la ruse diabolique ! » La ruse et la trahison dans la chanson polémique de l'époque hussite », Médiévales [En ligne], 67 | automne 2014, mis en ligne le 31 décembre 2016, consulté le 22 avril 2022. URL : http://journals.openedition.org/medievales/7397 ; DOI : https:// doi.org/10.4000/medievales.7397 
Sára Vybíralová

\section{"Oyez, fidèles, la ruse diabolique!» La ruse et la trahison dans la chanson polémique de l'époque hussite ${ }^{1}$}

Parmi les multiples «nouveautés » de la tumultueuse période de la révolution hussite, dues à la grande diversité sociale du mouvement, on peut mentionner l'extraordinaire expansion de la chanson comme support de transmission de l'information ${ }^{2}$. Elle assume désormais de nouvelles fonctions: la chanson polémique se fixe pour objectif de dénigrer ou de ridiculiser le parti adverse, la chanson «promotionnelle» défend les postulats et les revendications des hussites, la chanson de circonstance (ou «temporelle») sert à donner des informations sur des événements, souvent très récents, tout en affichant une prise de position ${ }^{3}$. Il va sans dire qu'émettre des distinctions entre ces genres est artificiel - les objectifs des textes se confondent. Les chansons puisent, d'une part, dans la tradition de la chanson populaire et liturgique plus ancienne et, d'autre part, accompagnent des textes ressortissant d'autres genres, destinés à un public différent mais dont les objectifs sont similaires - tels que les manifestes (écrits la plupart du temps en latin, destinés à un public étranger, noble ou instruit), les rapports ou même des traités.

1. Cette étude a été réalisée dans le cadre du projet «La perception des différences nationales en bas Moyen Âge: les pays tchèques comme un exemplum?», soutenu par l'Agence de la recherche scientifique de l'Université Charles de Prague (GAUK) ( $\left.{ }^{\circ} 24213\right)$.

2. Sur la question de la transmission de l'information, voir C.Boudreau, K. Fianu, C. Gauvard et M. Hébert éd., Information et société en Occident à la fin du Moyen Âge, Paris, 2004.

3. Jusqu'à aujourd'hui, c'est l'œuvre monumentale de Zdeněk Nejedlý sur L'Histoire $d u$ chant hussite qui reste, malgré ses imprécisions, l'ouvrage le plus pertinent et surtout le plus ample sur la chanson de l'époque: voir Z. NeJEdLÝ, Dějiny predhusitského zpěvu v Čechách, Prague, 1904 ; ID.,Počátky husitského zpěvu, Prague, 1907 et ID., Dějiny husitského zpěvu, t. 1-6, Prague, 1913. 
Une «popularisation » progressive de la production littéraire tchèque du Xve siècle, soulignée traditionnellement par les histoires littéraires ${ }^{4}$, et sa mise au service de l'idéologie vont de pair. C'est d'ailleurs cette dimension idéologique des genres littéraires populaires qui leur a valu d'être conservés. On peut parler de «popularisation», du fait de la rapide diffusion des postulats des docteurs réformistes liés à l'Université de Prague, due à l'efficacité de la prédication en langue vernaculaire. Cette tendance a été particulièrement marquante au sein de la conurbation pragoise ${ }^{5}$, où la chapelle de Bethléem, nouvellement construite à la fin du XIv siècle (1391) dans la Vieille Ville de Prague, et dédiée à la prédication en langue tchèque, a constitué une plateforme de propagande particulièrement efficace ${ }^{6}$.

Alors qu'il serait naif de voir dans les chansons polémiques une sorte d'expression immédiate et directe des couches sociales inférieures sans formation universitaire ${ }^{7}$, ces dernières leur étaient en revanche incontestablement destinées: il suffit de mentionner les incipits des chansons, qui contiennent très souvent une apostrophe d'apparence «démocratique» (par exemple: «oyez tous, les vieux et les enfants»). Ces chansons s'adressaient ainsi à «tous les Tchèques de bon nom [...]» ou aux «Tchèques de bonne foi». Les chansons, simples, compréhensibles et faciles à retenir, chantées souvent sur un air connu de tous ${ }^{8}$, avaient donc une diffusion large et rapide. Capables de dominer l'espace public, elles avaient un pouvoir performatif très fort ${ }^{9}$. En plus, elles n'étaient tributaires ni d'un support matériel ni de l'alphabétisation ${ }^{10}$. Comme le relate Prokop, le scribe de la Nouvelle Ville de Prague, dans sa chronique latine commencée en 1476, les partisans de Hus (c'est-à-dire les clercs) ont composé ces chansons «pour les laïcs», qui les chantaient «dans les églises, dans les tavernes, les chanteurs vaquant même de maison en maison ${ }^{11}$.

4. Z.Tı́HÁ, Cesta starší české literatury, Prague, 1984, p. 118 .

5. Rappelons qu'à cette époque, Prague se composait encore de plusieurs centres urbains distincts, dont chacun était doté de sa propre municipalité: la Vieille Ville et la Nouvelle Ville, fondée par l'empereur Charles IV en 1348, ne furent réunies qu'au XVIII' siècle.

6. Voir M.PerRet, «Vernacular Songs as "Oral Pamphletes": The Hussites and their Propaganda Campaign», Viator, 42/2 (2011), p. 371-391.

7. Dans les quelques cas où les noms des auteurs ont été conservés, il s'agit de clercs ou de commandants hussites - membres de la petite noblesse : voir J.DAŇHELKA éd. Husitské písně, Prague, 1952, p. 211.

8. J.НRавÁк, Dějiny české literatury, Prague, 1959, t. I, p. 200.

9. Se rapprochant, sur ce point, des crieurs publics: voir N.OFFENSTADT, «Les crieurs publics à la fin du Moyen Âge. Enjeux d'une recherche», dans Information et société en Occident..., p. 203-217.

10. Sur la force de la propagande orale, voir M.AuRell, «Chanson et propagande politique: les troubadours gibelins (1255-1285)», dans P.CAMmarosano éd., Le forme della propaganda politica nel Due e nel Trecento, Rome, 1994, p. 183-202.

11. J.Dañhelka, J. Hrabák et B. Havránek, Výbor zčeské literatury doby husitské, Prague, 1964, t. 2, p. 292.
Mais cet aspect fascinant des chansons de circonstance - leur oralité et leur «popularité»-constitue en même temps leur plus grand inconvénient en tant que sources: les textes conservés ne sont que des miettes par rapport à un corpus que nous pouvons supposer bien plus important. La chanson avait une vie éphémère et nous ne pouvons que rêver un recueil analogue à l'Hymnaire de Jistebnice ${ }^{12}$, célèbre collection de cantiques liturgiques et de chansons spirituelles en latin et en tchèque, consignés dans les années 1420. La transcription de ces textes était aléatoire. Le contexte de leur conservation présente d'ailleurs un intérêt intrinsèque: si elles n'étaient pas insérées dans des chroniques, elles faisaient souvent partie de codices ou de recueils regroupant du «matériel argumentatif» - tel que traités, notes, morceaux choisis, lettres remarquables - servant à soutenir une cause ${ }^{13}$. Quelques-unes se sont toutefois conservées dans des listes isolées en papier - des sortes de flyers $^{14}$-, ce qui suppose une volonté de diffuser le texte sous forme matérielle et de lui assurer ainsi une certaine pérennité. D'ailleurs, les chansons de circonstance devaient exister à une époque antérieure ${ }^{15}$ mais, faute d'un contexte propice à leur conservation, elles ne connaîtront un véritable essor qu'après le procès de Hus et disparaîtront de nouveau quand la situation politique en Bohême se stabilisera, à la fin du $\mathrm{Xv}^{\mathrm{e}}$ siècle. Cette apparition soudaine d'une littérature en langue vernaculaire, engagée et audacieuse, liée à une époque troublée empreinte de fortes animosités, permet de rapprocher les chansons hussites tchèques des sirventes occitans de l'époque de la croisade contre les Albigeois: comme elles, les sirventes avaient une vie éphémère ${ }^{16}$. Mais pour apprécier le rôle «journalistique» de ces «chansons d'histoire» fondées sur les événements du temps présent, il

12. L'hymnaire a été étudié de manière plus ample par Z. NeJEDLÝ, dans Dějiny husitského zре̌vu. Une première édition critique est en cours, mais pour l'instant, seul le premier volume a vu le jour: J.Kolár, A. VidManová et H. Vlhová-Wörner éd., Jistebnický kancionál, vol. I, Brno, 2005.

13. Tel est le cas, par exemple, de la chanson hussite Cher créateur, aie pitié, insérée dans un recueil de documents relatifs au concile de Constance et, plus particulièrement, la condamnation de Hus (Wien, ÖNB, ms.4557). Des recueils similaires de tendance antihussites existent également à l'époque du concile et plus tardivement.

14. C'est le cas de la courte chansonnette à la tonalité anti-taborite, composée de quatre strophes et racontant de manière sommaire la capture du copiste de la famille de Rožmberk, Jean de Srlín, par les habitants de Tábor, en 1441. Le revers ne porte qu'une date (celle de l'année suivante). Pour la dernière édition de la chanson, voir Výbor zčeské literatury husitské doby, t. II, p. 92.

15. Par exemple, Z. NejedLÝ mentionne la chanson latine, provenant probablement de Bohême, sur l'assassinat du roi de HongrieCharles d'Anjou (Dějiny husitského zpěvu, t. II, p. 170). Relatant un événement de 1386, elle fut transcrite (et était donc encore connue) en Bohême dans la seconde moitié du xv $v^{\mathrm{e}}$ siècle, où elle fut incorporée dans un recueil de chansons par Oldřiich Kř́iž de Telč, sans doute à cause de son caractère pamphlétaire contre le roi Sigismond.

16. M. AURELL, «Les sources de la croisade albigeoise: bilan et problématiques», dans M. RoQuebert et P. SÁncheZ éd., La Croisade albigeoise, Carcassonne, 2004, p. 21-38. 
suffit de penser aux cantastorie, une sorte de postérité de telles chansons à l'époque moderne, qui prirent une ampleur particulière au XIX ${ }^{\mathrm{e}}$ siècle.

De même que le mouvement hussite tout entier, qui gagna par la suite en Bohême puis en Tchécoslovaquie le statut de moment clé dans chaque synthèse de l'histoire nationale, les chansons de l'époque furent interprétées de manières diverses en fonction de l'idéologie régnante. Ainsi, l'éditeur du recueil des Chansons hussites (parues en 1952) ${ }^{17}$, Jiří Daňhelka, souligne «l'amour du chant inné de notre peuple», le considérant comme «un grand apport du hussitisme », tandis que l'éditrice Zdeňka Tichá affirme en 1984 que les chansons anti-hussites, présentant les traits formels de la littérature populaire, incarnent une littérature «faussement populaire», dont les créateurs «voulaient tendre un piège au peuple et le mettre en déroute» ${ }^{18}$.

Cette accusation surprenante, pleine d'émotion, nous fait entrer dans le vif du sujet: il y a quelques dizaines d'années seulement, Tichá a encore eu recours, pour souligner son propos et sa position idéologique, à une accusation de fausseté. De même que les auteurs médiévaux, l'éditrice mettait en garde les lecteurs: les opposants sont plus intelligents que les partisans de «notre» cause, ils trichent, ils conspirent, ils cachent leurs vraies intentions. Cette peur archétypale de la malice de l'autre traverse les époques. Elle apparaît d'une façon singulièrement marquante dans les textes de la période hussite à cause de leur partialité très prononcée. Si les éditeurs des principaux recueils de littérature médiévale tchèque, tous parus à l'époque socialiste, soulignent unanimement le «caractère populaire» de la littérature hussite, ils s'attardent moins sur un autre trait constitutif: la division rigoureuse de deux camps inconciliables et la vision presque manichéenne qu'ils affichent. La Bohême hussite offre donc un cadre idéal pour étudier la façon dont l'usage du lexique et les choix stylistiques deviennent un instrument axiologique, la manière dont ils structurent le regard porté sur l'autre et peuvent éventuellement être instrumentalisés (de façon consciente ou inconsciente).

Bien évidemment, l'aspect fallacieux de l'ennemi n'est pas le seul chef d'accusation ni même le plus fréquemment mentionné, a fortiori dans les textes d'inspiration hussite où reviennent sans cesse les motifs de la débauche, de la convoitise et de la corruption du clergé catholique. Mais si les manières de dénigrement sont multiples, l'accusation (ou même le soupçon) de fausseté me semble particulièrement intéressante à cause de l'émotion particulière qu'elle suscite. Il ne s'agit plus uniquement de dédain ni d'une simple condamnation: cette accusation exprime surtout de l'inquiétude. L'imprévisibilité du faux transgresse les normes, car elle s'oppose à la franchise et à la clarté - des valeurs estimées au Moyen Âge.

17. J.DañHeLKa, Husitské písně..., p. 205

18. Z. TíHÁ, Cesta starší české literatury .p. 100.
En plus, l'accusation de fausseté est un moyen axiologique nécessairemen bilatéral : celui qui trompe a toujours - même si ce n'est qu'implicitement besoin d'un dupé, d'une victime, qui est, par définition, dans une position passive et peu flatteuse.

Sans prétendre parvenir à présenter les chansons de l'époque dan toute leur complexité, nous fonderons notre analyse sur une douzaine de chansons déjà publiées, parmi lesquelles nous pouvons distinguer plusieurs groupes correspondant à différentes étapes. Au cours des premières années qui suivirent l'exécution de Jean Hus à Constance en juillet 1415, de nombreuses chansons utraquistes apparurent en réaction à cet événement Elles annoncent la nouvelle de la mort du célèbre prédicateur et la présentent à la manière d'une passion: Hus devient un martyr, les textes insistant sur son intégrité et son innocence, sans oublier le sauf-conduit accordé par le roi Sigismond et le concile, et soulignant in fine l'humiliation et l'insulte immense faite à ce docteur et, par son entremise, à tout le royaume de Bohême. Les chansons reprennent les motifs de textes de plus grande envergure (comme le rapport de Pierre de Mladoňovice ${ }^{19}$ ) ou plus instruits (comme les manifestes ${ }^{20}$ ), les simplifiant et les vulgarisant. D'autres chansons de la même époque, qui se concentrent moins sur Hus, dénoncent plus généralement la perfidie du concile et s'opposent au clergé local proconciliaire.

D'une époque légèrement postérieure (1419-1420) datent plusieurs invectives en vers anti-hussites, dont une chanson intitulée Réjouis-toi donc, sainte Église! ${ }^{21}$. Probablement composée pendant le concile de Constance ${ }^{22}$, cette dernière réagit à la défenestration des échevins de la Nouvelle Ville de Prague en juillet 1419, un événement majeur qui marque un coup de force amenant les militants du calice aux rênes de la municipalité de Prague ${ }^{23}$ Cette chanson fait donc suite à cet acte ${ }^{24}$.

19. Les rapports en latin de ce scribe, présent au concile de Constance, sur les procès et les exécutions de Jean Hus et de Jérôme de Prague, étaient souvent copiés.

20. Certains ont été édités dans F. M. Bartoš, Les Manifestes de la ville de Prague de l'époque des guerres hussites, Prague, 1932.

21. Již se raduj, cierkev svatá, dans Výbor zčeské literatury doby husitské..., t. I, p. 290292.

22. C'est ce qu'indique, du moins, une notice latine accompagnant le texte du poème dans le manuscrit. Rudolf Urbánek voit dans l'auteur de la chanson le polémiste catholique et l'adversaire acharné de Hus, Mařík Rvačka: voir R.URBÁNEK, «Mařík Rvačka jako proet l'adversaire acharné de Hus, Mařík Rvačka: voir R.URBÁNEK, «Marrík Rvač́a

23. Après un sermon du prêtre utraquiste radical Jean de Želiv, ses partisans ont attaqué la mairie de la Nouvelle Ville et tué treize échevins sous prétexte qu'ils avaient refusé de libérer les utraquistes emprisonnés. L'événement (le 30 juillet 1419) a précédé de peu la mort du roi Venceslas IV (le 16 août 1419) et annonce le début des guerres hussites: voir P.ČORNEJ, První pražská defenestrace, Prague, 2010.

24. Le même manuscrit porte une traduction imprécise en latin et une notice sur la dévastation du monastère des chartreux dans le faubourg praguois de Smíchov. 
Dès la fin des années 1420, après la stabilisation et l'organisation progressive du mouvement en réponse aux croisades anti-hussites dirigées par Sigismond, et avec la scission de plus en plus marquée du camp hussite en une branche radicale (les taborites et le parti de Jean de Želiv à Prague) et une branche modérée (dont une partie soutenait le candidat au trône Sigismond Korybut ${ }^{25}$ ), les textes de propagande utraquistes ne visent plus seulement le clergé catholique et les opposants de Hus, mais aussi d'autres adhérents au calice. C'est le cas de la chanson Les Tchèques de bon $n m^{26}$, qui raconte la prise, jugée traître, de Sigismond en 1427. Quelques quinze ans plus tard, en 1441 ou 1442, après les compactata de Bâle, une autre chanson de trahison a vu le jour - celle sur Jean de Srlín, le scribe d'Oldřich de Rožmberk, le grand baron catholique du sud de la Bohême. Elle témoigne des rixes continues qui avaient lieu au niveau local dans une Bohême déchirée.

Finalement, un dernier grand groupe d'invectives en chansons (mais qu'on trouve aussi dans d'autres types de supports ou de textes), liées à l'identité confessionnelle, se constitue autour de Jean Rokycana ${ }^{27}$, la tête de l'Église utraquiste et l'archevêque élu de Prague.

Les chansons polémiques suivent souvent le même modèle formel: elles s'ouvrent sur une invocation à Dieu ou une apostrophe adressée au peuple, à laquelle s'adjoint l'expression d'un vœu de réconciliation (évidemment à condition que les adversaires se convertissent!), et se concluent par une nouvelle invocation.

\section{Le lexique de la fausseté et les pièges de la langue}

Traiter d'une problématique qui se fonde sur l'usage du lexique d'une langue (le vieux tchèque) dans une autre langue (le français) peut évidemment être lui-même source de «traîtrise», ce qui invite à la plus grande prudence. Des équivalents existent, mais ils ne peuvent se superposer, ni du fait deleur étymologie, ni du fait de leur contenu sémantique, ni du fait

25. Sigismond Korybut, comte de Lituanie, s'est vu offrir la couronne royale tchèque par certains nobles. Arrivé en Bohême à la tête d'une armée, il s'est rangé au côté des armées hussites en conquérant la ville d'Uničov. À l'assemblée convoquée dans la ville de Čáslav en 1422, il fut nommé gouverneur du pays et continua à s'engager en tant que chef des armées jusqu'en 1427, où il fut dépossédé du pouvoir par un coup d'état à Prague, emprisonné et plus jusqu en 1427 , où il fut dépossédé du pouvoir par un coup d’état à Prague, emprisonné et plus
tard expulsé du pays.

26. Z dobrého jména Čechové, dans Výbor z české literatury doby husitské..., t. I, p. 327331.

27. Le théologien utraquiste modéré, Jean Rokycana (1396-1417), représentait le parti conciliant du mouvement hussite au concile de Bâle et était donc à l'origine des célèbres compactata. En 1435, il fut élu archevêque par la Diète de Bohême, mais il n'a jamais reçu l'investiture canonique. Les invectives ont été étudiées par J.BoubíN, Žaloby katoliku na Mistra Jana zRokycan, Rokycany, 1997. de leurs connotations. Commençons donc par quelques remarques sur les notions traduites ici par les termes de «ruse» et de «trahison».

Le nom lest, rendu ici par «ruse», dont dérive l'adjectif lstivý, est apparenté à l'allemand «die List», qui a le même sens, mais l'emprunt aux langues germaniques se fit de manière très précoce, avant la différenciation $\mathrm{du}$ vieux slave en branches individuelles. Le mot a eu d'abord le sens de « savoir $^{28}$ » avant de signifier «la ruse ${ }^{29} »$ ou «la feinte» et de se confondre dans certains cas, avec la trahison ${ }^{30}$. Ce terme est également très proche de chytrost, mot désignant simplement en tchèque actuel l'intelligence mais, en vieux tchèque, il se teinte de fortes connotations péjoratives et s'apparente à une «mauvaise» intelligence, une finesse d'esprit employée à de mauvaises fins, soit à la rouerie. De plus, le mot lest pouvait s'opposer à la vérité (pravda): ainsi, le clergé indigne, qui vend les indulgences, «change la vérité en ruse ${ }^{31} »$, terme qui devient alors synonyme de mensonge ${ }^{32}$.

La vérité $(\operatorname{pravda})$ est une notion extrêmement complexe en vieux tchèque. Étymologiquement dérivée de pravý (droit) et donc étroitement liée aux notions comme právo (le droit), správný (correct), přimý (droit, direct) ou prvý (le premier), elle s'oppose à la fois à tout ce qui est gauche et à ce qui n'est pas droit ${ }^{33}$, ce qui est tordu, donc au tort (křivý, křivda). Symptomatiquement, les deux sèmes - le tortueux et la gaucherie s'opposent sémantiquement à la sincérité et à la fidélité: aujourd'hui encore, křivák («le tordu») est un tricheur ou un malicieux, tandis que levota (la «gaucherie») équivaut à la notion de ruse (lest)

En vieux tchèque, pravda ne signifiait pas seulement la vérité opposée au mensonge, mais tout aussi bien la vérité religieuse, de même que la justice, le bien et, de manière générale, tout ce qui est bien, juste, correct, moral ${ }^{34}$. Pour les hussites, qui se prétendent les «partisans de la

28. J.ReJžEK, Český etymologický slovník, Prague, 2001, p. 339.

29. Vues les connotations fortement négatives du mot lest au Moyen Âge et son intention supposée, nous pourrions choisir de la traduire par «malice», mais je préfère la neutralité relative du mot «ruse» qui équivaut à la neutralité du mot lest en tchèque d'aujourd'hui et qui met plus l'accent sur l'action que sur la malice.

30. Cela est surtout marquant dans la célèbre chronique tchèque du début du XIV ${ }^{e}$ siècle dite Chronique de Dalimil. Le nom lest y est souvent accompagné par un verbe renvoyant à l'idée de piège ou de conspiration (klásti «tendre», skládati, «composer, machiner»): voir J.GeBAuER, Slovník staročeský, Prague, 1916.

31. J.DAŇHELKa, Husitské písně...., p. 86.

32. Une formulation presque identique sur le changement de la vérité revient dans une chanson composée par Jean Čapek de Sány, mais avec le mot «mensonge» (lež) à la place de celui de «ruse» (lest)

33. Sur la valorisation de la droite au profit de la gauche, voir l'article classique de R.HERTZ, «La prééminence de la main droite. Étude sur la polarité religieuse», Revue philosophique, 34 (1909), p. 553-580.

34. Sur la notion de vérité dans les écrits latins et tchèques de Hus, voir F. M. B ARTOŠ, «Pravda v pojetí M. J. Husa», Jihočeský sborník historický, 18 (1948), p. 38-41. 
vérité », pravda représente donc un postulat fondamental et incarne l'ordre du monde qu'ils promeuvent. Dans ce sens, elle devient synonyme de pravá viera («la vraie foi»), qui n’indique pas seulement l'appartenance confessionnelle, mais aussi l'ordre et la justice. Aussi est-elle traduite par iusticia par Claretus, l'auteur du premier glossaire bilingue latin-tchèque ${ }^{35}$, datant du milieu du XIV ${ }^{\mathrm{e}}$ siècle. La vérité (pravda) s'approche donc de la vertu de la fidélité/loyauté (viera, viernost); les deux notions se rejoignent par leurs antonymes qui sont extrêmement proches. Le tableau suivant montre les équivalents latins-tchèques proposés par Claretus dans le chapitre $D e$ moribus de son Glossarius:

\begin{tabular}{|l|l|}
\hline PRAVDA (la vérité) - veritas & $\begin{array}{l}\text { - LEŽ (le mensonge) } \\
\text { - LEST (la ruse) - falsitas } \\
\text { - KŘIVDA (le tort) }\end{array}$ \\
\hline $\begin{array}{l}\text { PRAVDA = pravá viera (la vraie foi) } \\
- \text { iusticia }\end{array}$ & - KŘIVDA (le tort) - iniquitas \\
\hline $\begin{array}{l}\text { VIERNOST (fidélité, loyauté) } \\
\text { - fidelitas }\end{array}$ & $\begin{array}{l}\text { - NEVIERA (l'infidélité) - perfidia } \\
\text { - ZRADA (la trahison) - proditio }\end{array}$ \\
\hline
\end{tabular}

Les relations d'antonymie de quelques notions fondamentales en vieux tchèque et leur traduction latine proposée par Claretus

La ruse est donc une notion très floue qui s'opposait à la fois à la vérité (par le faux-semblant qu'elle implique) et à la fidélité. Elle s'approche aussi bien du faux, du tort, de l'injuste (křivda) que de la malignité (chytrost).

La notion de trahison (zrada ou prorada, prorazenie) occupe une position extrême dans l'axiologie morale. À la différence de la ruse (qui peut simplement indiquer un caractère suspect, indigne de confiance), la trahison implique plus clairement une action hostile. Quelques emplois parallèles attestent sa synonymie occasionnelle avec l'infidélité (neviera) ${ }^{36}$.

35. Les deux œuvres du mystérieux érudit Bartholomaeus de Solencia dictus Claretus (connu en tchèque comme Bartoloměj de Chlumec, dit maître Klaret) - le Bohemarius et sa continuation, le Glossarius -, sont divisées en chapitres correspondant à des domaines thématiques. Les entrées sont rangées en vers et ne suivent pas l'ordre alphabétique. Pour chaque notion latine, une ou deux traductions tchèques sont proposées. Les notions concernan la vérité et la foi et leurs antonymes proviennent du chapitre De moribus du Glossarius. Sur verité et la foi et leurs antonymes proviennent du chapitre De moribus du Glossarius. Sur Caretus, voir V.FLAJŠHANS, Klaret a jeho drużina, t. I-II, Prague, 1926. l'encontre de la noblesse tchèque avant la bataille de Vyšehrad, que rapporte le chroniqueur Laurent de Březová. Selon Laurent, Sigismond aurait dit: «Vous, les Tchèques, m’êtes infidèles» (non fideles), ce qui aurait poussé les vaillants nobles à se précipiter au combat avec un tel élan que beaucoup d'entre eux y seraient morts. La même situation apparaît dans une lettre/manifeste des Praguois destinée aux nobles: dans cette lettre en tchèque, Sigismond a «traité les nobles tchèques de traîtres» (VAV̌̌INEC z BŘEzové, Kronika husitská, éd. J. Goll, FRB V, Prague, 1893, p. 441-445).

\section{Tirant les flèches de la rouerie : la ruse comme topos littéraire}

Bien évidemment, la topique de la ruse n'est pas une innovation de l'époque hussite. Dans la satire du $\mathrm{XIV}^{\mathrm{e}}$ siècle, la ruse était attribuée à certain personnages ou à certains groupes, parfois comme qualificatif récurrent: elle était surtout assimilée aux femmes en général (dont «la foi est aussi sûre// que le trou dans la clôture» ${ }^{37}$ ), mais aussi aux échevins (prononçant des sentences fausses et injustes par convoitise ${ }^{38}$ ) et, parmi les animaux, au renard.

Dans la longue introduction allégorique de la version tchèque des fables d'Ésope qui raconte la guerre des vertus et des vices, la guerre contre la Vertu est déclarée par la Colère et le Tort (křivda), mais la Ruse (lest) et l'Infidélité (neviera) sont leurs premiers alliés, toutes deux amenant avec elles de nombreux soldats «tirant les flèches de la malignité» (chytrost). Elles sont habillées de douces paroles, mais c'est l'Infidélité qui se porte à la tête de l'attaque pour causer, en collaboration avec les autres vices, de graves dommages à la Vertu et la pousser à se réfugier dans un endroit isolé à la montagne ${ }^{39}$.

La déloyauté et la fausseté apparaissent aussi dans des prologues moralisants d'œuvres littéraires en tant que contraires naturels de la vertu. Le schéma général de l'intrigue est donc esquissé d'avance. Ainsi s'ouvre par exemple l'une des rares chansons de gestes en tchèque, Le Duc Ernest

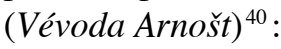

Car les loyaux obéissent à l'honneur

et sans cesse en nourrissent leur âme,

ils sont toujours aimablement à l'écoute,

mais les déloyaux, les méchants, les faux,

les gens à double face et les malicieux

quand ils s'aperçoivent qu'un tel se comporte honorablement,

37. J.Kolár et E. Praž́́k, Barvy všecky, Prague, 1982, p. 85. Ce thème revient auss dans plusieurs dictons laconiques sur la «ruse et malice» des femmes: voir J.VILIKOvSKY, Staročeská lyrika, Prague, 1940, p. 168-172.

38. La satire des années 1370, faisant partie du cycle satirique du Manuscrit de Hradec, attaque surtout la corruption des échevins, mais elle porte le titre Sur les échevins déloyaux $(O$ konšelích nevěrných). Pour l'édition de ce texte, voir J.Hrabák éd., Staročeské satiry Hradeckého rukopisu a Smilovy školy, Prague, 1962, p. 95.

39. Voir B.HavráneK, J.HraBák et al., Výbor zčeské literatury od počátkủ po dobu Husovu, Prague, 1957, p. 548. Les fables d'Ésope ne sont pas datées; leur manuscrit fai partie du Recueil de Baworowski de 1472.

40. D. MaREČKová et E. Petrư éd., Rytiřrské srdce majíce. Česká rytiřrská epika 14. stolet Prague, 1984, p. 25. Il s'agit de la traduction actualisée d'une chanson allemande, réalisée dans la seconde moitié du XIV ${ }^{\mathrm{e}}$ siècle. 
ils se mettent tout de suite à le blâmer avec ruse,

en le calomniant par colère.

Toute fausseté est fondamentalement négative ; ce n'est pas par hasard si les caractéristiques qui en relèvent (la ruse, la déloyauté, l'infidélité) font partie d'un ensemble de vices étroitement associés (tels les alliés du prologue des fables d'Ésope): qui est déloyal doit impérativement être méchant. Pourtant, si les héros rusent, leurs actions ne sont pas nécessairement nommées comme telles: dans la célèbre histoire de la Chanson de Tristan (dont il existe une traduction de l'allemand en vieux tchèque, Tristrama Izalda, datant de la fin du XIV $^{\mathrm{e}}$ siècle), les deux jeunes héros trompent le roi Marc en employant fréquemment d'ingénieuses astuces; pourtant le narrateur ne parle jamais de trahison, ni de ruse, une seule fois de la malignité (chytrost) dans le cas d'Izalda. En revanche, ceux qui dénoncent les amants au roi sont «les traîtres». La dénonciation elle-même est appelée «trahison». Tristram, en revanche, est qualifié à plusieurs reprises de nelstivý - loyal, littéralement «non rusé ${ }^{41}$. L'auteur se sent néanmoins obligé d'expliquer que les héros sont complètement sous l'emprise du philtre d'amour qui les rend irresponsables de leurs actes; la suprématie de l'amour courtois y renverse l'optique morale. La notion de ruse est donc moins ambiguë qu'il ne pourrait sembler. Si les astuces sont divertissantes et font rire dans les farces justement à cause de leur caractère transgressif, la ruse n'en est pas moins taboue, d'autant plus qu'elle s'oppose à la vaillance et donc à l'idéal chevaleresque en général ${ }^{42}$.

Si la candeur, comme celle, prétendue, de Tristram, représente l'idéal, les textes de tous genres - dictons, exempla, satires, en passant par de nombreuses moralités, jusqu'à la littérature courtoise - insistent sur la nécessité de la méfiance. Les exempla aussi bien que certains proverbes soulignent une certaine prise de risque: celui qui trompe sera trompé. La supériorité de la loyauté est affirmée par la promulgation de sa prétendue victoire, comme dans le court dicton: «La déloyauté (nevěra) trompera la déloyauté, mais la loyauté (viera) la vaincra ${ }^{43}$.»

41. Tristram a Izalda, éd. Z. Tiché, Prague, 1980.

42. Dans le roman de Troie en tchèque, au moment du partage du butin, Ulysse est accusé devant le roi Agamemnon par Télamon Ajax: «s'il [Ulysse] dit que nous avons conquis Troie grâce à lui, ce n'est pas par sa vaillance, mais par ses paroles fausses et traîtres, pour lesquelles nous serons déshonorés à jamais auprès de toutes les nations humaines, puisque nous avons vaincu les Troyens par nos roueries, faussetés et feintes tandis que nous aurions dû les vaincre par la force de notre vaillance.» (Trojánská kronika, J. DaňHELKa éd., Prague, 1951, p. 250-251.) La Chronique de Troie (Kronika trajánská) en tchèque se fonde sur la version latine de Quido de Columna, datant de 1287.

43. J.VIUKOVSKÝ, Staročeská lyrika.... p. 168.

\section{Les rusés et les innocents : le lexique de la (dé)loyauté au service de l'auto-affirmation et du dénigrement}

L'usage de la langue vernaculaire pour le chant ecclésiastique et, par conséquent, une meilleure compréhension du rite par un plus large public, a constitué l'un des principaux points de discorde entre les partisans de la réforme et les catholiques. Quelques chansons utraquistes spirituelles, conservées dans l'Hymnaire de Jistebnice, expliquent en effet la méfiance de l'Église envers l'introduction de la langue vernaculaire: les textes des chansons mêlent souvent habilement les motifs religieux au ton polémique et aux invectives. Ainsi, la chanson intitulée Réjouissons-nous tous à présent, destinée à être chantée le jour de la Résurrection, associe une célébration de la Résurrection du Christ à une invective profondément révolutionnaire contre l'Église. La constitution de l'Église y est présentée comme une sorte de conspiration $^{44}$ :

Quand les évêques, cette race de serpent, ont entendu la nouvelle,

alléluia,

Ils se sont tout de suite assemblés

et ils ont conspiré une trahison

alléluia,

en se disant qu'il fallait voler Jésus

pendant que nous dormions

alléluia.

Les chansons spirituelles hussites célèbrent donc Dieu tout en valorisant la communauté religieuse utraquiste ainsi que leur précepte fondamental, la vérité, une vérité nouvelle aux yeux de l'Église mais qui, selon les hussites, ne fait que rétablir l'ordre primordial. Et c'est justemen l'idée de la fausseté de l'Église qui est mise au service d'une telle notion.

La chanson Notre Créateur, aie pitié, créée entre 1416 et 1418, s'attaque au clergé anti-réformateur et conciliaire. Ayant la forme classique d'une chanson polémique, commençant par une apostrophe (ici, l'invocation de Dieu) et s'achevant par le souhait de voir les adversaires se convertir, elle critique le clergé qui attend une décision du concile sur la question du calice. Le fait que les catholiques refusent de se subordonner aux arguments de la Bible (dont la chanson propose deux citations simplifiées, fournies par de nombreux traités), suffit pour les accuser de ruse, de mensonge et de fausseté. Les adversaires du calice sont traités de «race méchante du serpent» et font l'objet d'accusations comme: «Tu veux devenir trop

44. J. DaŇHELKa, Husitské písně..., p. 53. 
maligne $^{45}$ !» Cette prétendue volonté de l'emporter sur l'Écriture par «chytrost», terme qui désigne tout aussi bien le savoir que la ruse, s'attaque à la capacité la plus précieuse du clergé - son savoir ${ }^{46}$. Quelques strophes plus loin, le poète rappelle que, même si le concile dure depuis plus de deux ans, il n'a encore «fait rien de bien, ils ont seulement tué deux bons maîtres ${ }^{47} \gg$. Il pose alors une question rhétorique ${ }^{48}$ :

Oh, malheureux peuple,

qui s'insurge contre l'Écriture!

Pourquoi affirmez-vous l'hérésie

en machinant une ruse mensongère?

Le poète revient ensuite une nouvelle fois sur l'idée de machination: cette fois-ci, l'adversaire machine «un nouveau mensonge» («nouveau» prenant ici un sens péjoratif). S'opposer à la Vérité n'implique donc pas seulement «avoir tort», mais nécessairement vouloir avoir tort. Le motif du serpent (métaphore du diable, de la séduction et de la ruse), qui apparaît également dans d'autres chansons, le montre très clairement.

En regardant dans l'autre camp, la chanson catholique de la même époque, Réjouis-toi donc, sainte Église!, constitue un répertoire de reproches courants faits aux utraquistes: la violence, l'ignorance, l'hérésie. La ruse y est associée à la violence: "Vous êtes furieux comme les taureaux.// les vaches, les souris, les Maures.// Le brigandage, le meurtre, la ruse, et non pas le christianisme,$/ /$ telle est votre religion ${ }^{49}$.» Mais cette chanson, qui a pour refrain «Malheur à toi, Hus », a recours à un arsenal suprême : l'auteur traite les hussites de «traîtres de l'ordre de Dieu».

Aucune accusation ne peut être pire que celle de trahison envers Dieu. L'erreur religieuse est ici rapprochée du crime suprême dans la hiérarchie médiévale, et est considérée comme bien plus odieuse que le simple meurtre. La trahison ne figure pas dans les recueils de lois tchèques mais, dans certains codes de droit pénal (par exemple en Angleterre), elle entraîne la peine suprême (et spectaculaire) et suscite surtout une procédure extraordinaire. Rappelons que, dans l'Enfer de Dante, les traîtres occupent le dernier cercle de l'Enfer et c'est le Traître par excellence, Judas, qui est placé au centre de toute une typologie hiérarchisée des traîtres, présidant l'assemblée avec Lucifer en personne. Aussi le vocabulaire de l'Enfer apparaît-il à plusieurs reprises dans le texte: les hussites se révoltent «infernalement», guidés par la «ruse diabolique». Pour parler de la défenestration des échevins de la

45. « zlé, hadové pokolenie» (Výbor z české literatury doby husitské..., t. I, p. 275)

46. «Vous voulez être plus savants que Dieu», répète le poète un peu plus bas.

47. C'est-à-dire Hus et Jérôme de Prague (ibid., p. 278).

48. Výbor z české literatury doby husitské..... I. I, p. 275.

49. Ibid.,p. 291.
Nouvelle Ville en 1419, l'auteur emploie de plus un néologisme intéressant, attesté nulle part ailleurs, composé des mots «diable» (̌̌ert) et «trahison» $(z$ rada $)$ : «la trahison diabolique» $(\check{c} r t o z r a d a)^{50}$

Pourtant, ils ont, par la ruse et la trahison diabolique assassiné le conseil praguois,

des honnêtes échevins de la Nouvelle Ville,

attendez-vous à une mauvaise fin!

Malheur à toi, Hus!

Toujours au cours des années soixante, dans une chanson polémique anti-utraquiste tardive contre Jean Rokycana ${ }^{51}$, il semble qu'appartenir à l'«hérésie» constitue un fondement suffisant pour être accusé de ruse. L'archevêque utraquiste y est traité d' «apostat rusé» (odřezanec lstivý) et ses partisans sont des imposteurs (šibalníci), sans que l'accusation se concrétise. Celui qui interprète l'Écriture à sa façon la fausse - il est donc fondamentalement faux et devient l'instrument du diable. Dans cette invective plutôt confuse (accusant Rokycana à la fois d'hérésie et de convoitise, d'abus de pouvoir, de relation charnelle avec une veuve pragoise bien connue), un motif particulièrement important se distingue, présent dès le début: celui de la séduction. Comme le serpent biblique, l'anti-héros de la chanson a une capacité de séduction extraordinaire, justement grâce à son esprit rusé. L'invective «séducteur» revient à plusieurs reprises à propos de Rokycana: il est «le séducteur arianiste» ${ }^{52}$, le «séducteur de toutes les âmes simples,// le buveur du sang humain». Cette mise en garde contre le pouvoir de persuasion de Rokycana arrive avant toutes les autres accusations : c'est son plus grand danger. De plus, le charmeur du peuple se plaît, en conformité avec le diable, à semer la discorde et par conséquent l'infidélité. La déloyauté est contagieuse ${ }^{53}$ :

Quand le diable l'eut apporté à Prague,

le mettant sur ses cornes,

il a semé la discorde

et il a fait des gens des imposteurs;

camarade ne croit plus au camarade.

La littérature tchèque connaît aussi des œuvres poétiques visant plus directement des personnes particulières. Il s'agit des poèmes du Manuscrit

50. Výbor zčeské literatury doby husitské..., t. I, p. 292

51. «Les Tchèques de la bonne foi» (Cechové viery pravé), dans Ibid., t. II, p. 85.

52. Une confusion ou comparaison de l'hussitisme aux hérésies plus anciennes est fréquente.

53. Výbor z české literatury doby husitské..., t. II, p. 86. 
de Bautzen, qui contient trois longs poèmes allégoriques et quelques textes en prose avec leurs traductions latines, ayant tous le même objectif: dissuader la noblesse tchèque de s'allier au roi Sigismond. Les chansons ont vu le jour dans le contexte de la préparation de la première croisade contre la Bohême en 1420. L'importance accordée à la ville de Prague fait penser à un auteur provenant du milieu universitaire. Les poèmes, et plus particulièrement deux d'entre eux (L'Accusation de la couronne tchèque et La Complainte de la couronne tchèque $)^{54}$, ont à peu près la même structure, énumérant les défauts et les crimes passés de Sigismond, roi étranger, et «assassin» de son épouse, la couronne. Il est très révélateur que, si l'accusation de déloyauté revient ici à propos du roi, ce n'est qu'avec de grandes précautions. Le roi peut être traité de méchant, de cruel, furieux et lâche à la fois, mais jamais de traître, même si la lamentation insiste sur de multiples emprisonnements ordonnés en dépit de sauf-conduits accordés. Mais pour terminer, l'auteur joue encore sur la corde nationaliste, antiallemande, bien enracinée dans la littérature (et peut-être dans la société) tchèque. Et voici que survient finalement la trahison. Car Sigismond, un Luxembourgeois, pourrait privilégier les Allemands ${ }^{55}$. Et ces derniers sont «toujours les dénonciateurs, les calomniateurs, les meurtriers, traîtres à l'égard des Tchèques ». Ils doivent donc être chassés du royaume (à part ceux qui «sont fidèles à la loi divine », c'est-à-dire adhérents au calice). Ce n'est qu'après que «la trahison, les torts, les maux disparaîtront» et que la concorde règnera. L'inclination à la trahison est ici indissolublement liée à l'altérité et, ce qui est frappant, elle n'est jamais justifiée: il n'est pas nécessaire de «commettre» une trahison pour être traître (et être blâmé comme tel)

Parmi les chansons de circonstances (appelées parfois «historiques» à cause de leur aspect narratif), on peut distinguer un type de chansons s'articulant autour d'une trahison: les chansons reposant sur le motif de la capture.

Les chansons de capture de l'époque hussite, réagissant à un événement concret, ont un précédent littéraire plus ancien. La Chanson sur Stemberk, rappelant par sa forme une ballade populaire, raconte l'histoire d'un noble, amoureux d'une jeune fille de la ville de Mělník. Il est poursuivi par les bourgeois de Mělník et, quand il s'apprête à leur tirer dessus, ces derniers l'interpellent, lui promettent de ne pas le toucher et le supplient de ne pas tirer. Quand il obéit, l'un des bourgeois lui coupe tous les membres en dépit de leur promesse (ici appelée sauf-conduit, même si elle n'était

54. J.DañHelKa, Husitské skladby budyšínského rukopisu, Prague, 1952

55. Sur le nationalisme en Bohême à l'époque hussite, voir F. ŠMAHEL, Idea národa v husitských Čechách, Prague, 2000. qu'orale). Encore vivant, Stemberk regrette de s'être fié aux bourgeois. Tel est également l'enseignement de la chanson ${ }^{56}$ :

C'est pourquoi je dis au vieux, au jeune,

À celui qui est libre sur le champ de bataille:

n'accorde jamais une telle confiance!

Les deux chansons postérieures suivent la même structure: elles soulignent la naïveté du héros capturé et sa confiance presque candide contrastant avec l'hypocrisie et la cruauté des ravisseurs. Tel est le cas de la chanson catholique portant sur la capture du scribe (et espion ${ }^{57}$ ) des Rožmberk, et de la chanson sur la capture de Sigismond Korybut, bien qu'elles soient très différentes d'un point de vue qualificatif et quantificatif. Ainsi, les ravisseurs de Srlín:

\section{Ils l'ont surpris à minuit \\ quand il était sans défense \\ car il se fiait trop à eux \\ et il ne se doutait pas \\ de ce qu'il devrait fuir.}

Non seulement le héros ne se doute pas de ce qui lui arrivera, mais il a entière confiance en ceux qui lui feront du mal. Le pathos est poussé à l'extrême lorsque Srlín est comparé à Jésus (les ravisseurs sont armés comme les soldats qui sont entrés dans le jardin de Gethsémani). L'expression «les manières juives» (c'est-à-dire traîtres) ou «de Judas» revient d'ailleurs très souvent des deux côtés comme symbole de la perfidie dans les accusations, surtout à l'époque du concile de Constance: la candeur de Hus fait aussi partie de sa sainteté. L'innocence active, christique, et la fausseté «juive»- une intentionnalité cachée et meurtrière des bourreaux du Christ - s'opposent tout naturellement. À lui seul, Judas représente une puissante étiquette de dénigrement, associant la vénalité ${ }^{58}$, la défaillance et le détournement du Christ - donc de la foi.

56. J.VILIKovsKÝ, Staročeská lyrika..., p. 105.

57. Le cas de Srlín est connu par des lettres échangées entre le bourgmestre de Tábor et d'Oldřich de Rožmberk: Srlín faisait office de médiateur entre son parti et un allié secret de son maître dans le camp de Tábor (le scribe Peša) qui a révélé son nom après la découverte de sa trahison. Aux yeux des taborites, Srlín avait donc lui-même profondément trempé dans une trahison. Les lettres sont éditées dans F.PALACKÝ éd., Archiv český, t. I, Prague, 1840, p. 358-360.

58. Dans une chanson hussite pamphlétaire contre le clergé catholique, on compare ains le clergé simoniaque à Judas: «ceux qui vendent les sacrements// sont comme Judas// qui pouvait en vendre» (J.DAŇHeLKA, Husitské písně..., p. 84). 
De manière très similaire, la chanson sur la capture de Sigismond Korybut souligne la confiance du gouverneur envers ses traitres. Ce dernier se «fiait plus à eux qu'à d'autres». La chanson, qui a le caractère d'un pamphlet très concret (énumérant tous les intéressés par leurs noms), compare également un des participants au complot (un bourgeois de Prague, Svojís de Zahrádka) à Judas. Même si Sigismond Korybut ne fut pas tué lors de l'attentat, l'emploi d'un lexique extrême (Judas, trahison) et l'accentuation narrative de la confiance de la victime et de la perfidie des putschistes soulignent l'importance de l'événement et cherchent à infléchir l'opinion de l'auditeur par son argumentation émotive ${ }^{59}$, s'appuyant sur le pathos au détriment du logos.

Les manières d'instrumentaliser le motif de la ruse dans la chanson de l'époque hussite révèlent une association consubstantielle entre la vertu et la franchise d'un côté, la mauvaise foi et la déloyauté de l'autre. La ruse, qui associe en soi une nature profondément vicieuse et la malignité - la mauvaise forme de sapience - en s'opposant à la fois à la vérité et à la fidélité, apparaît dans la littérature polémique comme un trait constant de l'ennemi. Sa ruse rend l'ennemi d'autant plus dangereux. L'accusation suscite la peur, elle réveille le pathos.

Par un effet de miroir, la naïveté, dans la mesure où elle est contraire à la ruse, constitue un trait valorisant: la ruse de l'ennemi peut justifier un échec, une imprudence, comme on le voit dans les chansons de capture. Pour la victime, il n'est pas honteux de succomber à celui ou à ceux qui transgressent les règles, au contraire. Le héros-victime, héritier des saints martyrs des légendes, fait concurrence au héros vaillant.

L'accusation de trahison est employée dans les chansons comme un moyen de dénigrement ultime, que ce soit au niveau personnel ou au niveau général (visant un groupe). Dans ce second cas, les seuls groupes à pouvoir en être accusés, dans un contexte axiologique, sont les hérétiques ou les étrangers. En même temps, l'accusation de trahison portée à l'encontre de l'autre implique presque nécessairement sa propre valorisation. En tant que «label», la trahison a un pouvoir effectif de souillure, puisqu'elle entraîne la perte de l'honneur et devient surtout, avec un média tel que les chansons, une véritable arme publicitaire. C'est pourquoi certaines chansons (comme Les Tchèques du bon nom) insistent sur les noms concrets.

Si nous nous amusions cependant à effectuer des statistiques, le premier à se voir attribuer le caractère rusé serait... le diable. «La ruse diabolique» revient sans cesse dans les chansons des deux parties, presque comme le mobile caché de tous les maux. La prière adressée à la Vierge tation dans le discours, Paris, 2010. dans une chanson hussite - la mère du Christ étant priée de débarrasser ses fidèles du «méchant meurtrier, du diable rusé ${ }^{60} »$ - traduit l'ancrage de la pensée de l'époque dans le système axiologique fourni par la religion. L'omniprésente ruse diabolique exprime une sorte de paranoïa généralisée d'une époque où les prophéties eschatologiques se multiplient ${ }^{61}$. La mise en cause de la vérité religieuse paraît profondément inquiétante ${ }^{62}$ :

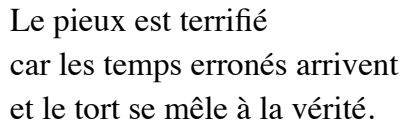

Sára VyBíRALovÁ - Université Charles de Prague, Faculté des Lettres, Département de l'histoire tchèque (ÚČD FF); École des Hautes Études en Sciences Sociales, Paris.

\section{“Oyez, fidèles, la ruse diabolique !» La ruse et la trahison dans la chanson} polémique de l'époque hussite

C'est à l'époque des guerres hussites que les chansons polémiques connurent, en Bohême, un premier essor en tant qu'outil publicitaire. Dans ce cadre textuel, le motif de la ruse et de la traîtrise, formant déjà un topos dans la littérature tchèque plus ancienne, devient un des traits constants de l'ennemi. Opposée de manière radicale à la fidélité et à la vérité, une telle accusation implique une certaine paranoïa et s'adresse aux émotions : dan l'argumentation, le pathos l'emporte au détriment du logos.

chanson - hussitisme - polémique - propagande - ruse - trahison

\section{"Listen, you faithful, the evil ploy !" Ploy and Betrayal in Polemic Songs of} the Hussite period

During the period of the Hussite riots, the polemic songs were frequently used in medieval Bohemia as a means of propaganda. The ploy and betrayal motif, already a literary topos in older Czech literature, becomes in this specific context one of the main characteristics of the enemy. Utterly opposed to fidelity and truth, the accusation of treason implies a kind of paranoia and favors an argumentation addressing the emotions : pathos overcomes logos. song - Hussitism - ploy - polemics - propaganda - treason

60. J. DaňHelKa, Husitské písně..., p. 39

61. P. Cermanová, Cechy na konci věkưu, Prague, 2013.

62. «La chanson sur la Vérité», dans J. Kolár et E. Pražák, Barvy všecky....p. 85. 
